\title{
The Influence of Advertising Co-creation on Brand Building on the Perspective of Value co-creation Theory
}

\author{
Run $\operatorname{Tan}^{1, *}$ \\ ${ }^{1}$ Xiangzhou District, Zhuhai City, Guangdong Province, China, United International College (UIC), Division of \\ Culture, Creativity and Management \\ "n830024229@mail.uic.edu.cn
}

\begin{abstract}
The traditional concept of value creation holds that value is an one-way output by enterprises to consumers, and consumers are only responsible for the acceptance and use. However, with the development of network economy and the diversification of marketing communication, the subject of value creation has gradually changed, and the focus has shifted from enterprises to consumers. Consumers actively participate in the process of value creation, and value will be created jointly by consumers and enterprises. Among them, user-co-created advertising is one of the relatively new ways of value co-creation. Users can bring more benefits to brands by participating in the creation of brand advertisements. Brand is the brand of consumers, consumers take the initiative to participate in the construction of brand advertising, which will become a trend. Based on the value co-creation theory, this paper finds that user-co-created advertising has a promoting effect on brand building, and enterprises should make good use of this measure to strengthen brand building.
\end{abstract}

Key words: Value co-creation, advertising co-creation, brand building, marketing strategy, marketing value

\section{INTRODUCTION}

According to the traditional value creation theory, value is one way to output by enterprises to customers, and customers are only a recipient of value. However, with the rapid development of network technology, the role of customers has undergone a significant change. Existing technology not only makes the diversified needs of customers more easily perceived and transmitted, but also enables customers to take the initiative and actively participate in the process of value creation [1]. Enterprises actively interact with customers online and offline, seek cooperation with customers and understand their needs, so as to create value together. At present, a large number of literature agree with the value co-creation theory, and have studied its connotation and development mechanism, but they are more inclined to the macro aspect, and very few have studied the specific co-creation behavior and strategy. In fact, the value of a product is reflected in functions, characteristics, quality and other aspects. With the increasingly fierce market competition, the importance of advertising in product competition is gradually rising. A good advertisement can bring infinite added value to the product. This paper first introduces the connotation of user-co-created advertising, then analyzes the benefits of user-co-created advertising to brand building based on the value co-creation theory, and finally puts forward the promotion strategies for enterprises to adopt co-created advertising.

\section{ANALYSIS}

\subsection{A brief overview of value co-creation and user-advertising co-creation}

The connotation of value co-creation theory can be discussed in three contexts: production field, consumption field and network environment [4]. The focus of the production field is how to make customers participate in value creation, emphasizing the process of how customers interact with enterprises as co-producers and create value. Therefore, value co-creation in the field of production is also called value co-production, 
whose value source is the use value of customers, while demand comes from the perceived customer demand of enterprises. In the consumption field, customers are the leader of value co-creation, and their professional knowledge and skills become the key source of competitive advantage of enterprises, and they unite with enterprises and integrate resources together to create value. In the network environment, consumers' individual needs are more easily perceived and transmitted. Value creation main body under the network environment become more complex, the network virtual brand communities for the customer and the enterprise, customers to interact with customers to provide more free space, interactive opportunity also is much bigger than offline [6], such as suppliers, business partners, associates and customers can participate in different subjects and freedom of interaction and sharing of personal experience among them, It realizes the value co-creation mode of unified production field and consumption field.

Co-creation of advertising based on users in the network environment is also one of the ways that users and enterprises create value together. The enterprise publishes the solicitation order of advertisement content through the network social media, and the users can put forward suggestions for the content style of advertisement according to the characteristics of the brand, which has a strong entertainment nature. This soup's advertising can cause a heated debate on the Internet, Soup's got talent and brand ambassador in Weibo, Bilibili with new AD platform, but unlike previous video, the film has long gray unfinished animation, also marked the background to the grand opening. Users thought it was the wrong source of the video, but Soup's got talent brand said that this is to start an activity of "shooting an advertisement with Soup's got talent", hoping that in this unfinished form, users will be invited to become the builder of The original soup, describe the imaginary world of the soup, and jointly complete the brand promotion video. Eventually, people will put the ID of the idea at the end of the full TVC as a signature, creating the "longest signature commercial". With the changing mobile Internet environment and the rise of young consumers, marketing methods have undergone new changes. Creating brand with users, infiltrating users' thinking into every link of brand marketing, has become the current way of brand marketing. Let users participate in brand marketing communication, not only can effectively reduce the cost of communication, but also can make the communication range wider, deeper, faster, so as to bring continuous flow. Soup's communication has gone beyond the framework of ad film production-publishing-interaction, but has brought interaction forward to the production process, making the user not only a viewer and a sharer, but also a creator who can participate in opinion discussions, thus enabling the whole marketing to achieve a longer-tail communication effect.

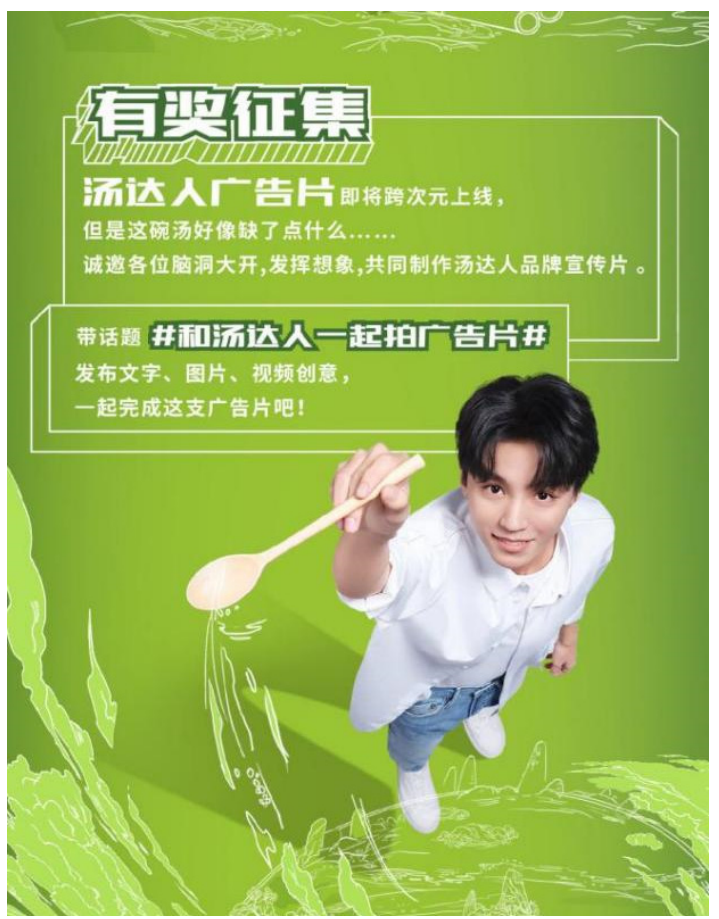

Figure 1 The co-create advertising posters from soup users

At present, the market is gradually saturated, and advertising assimilation is serious, which has little effect on promotion, but the lack of advertising is not good either. From the perspective of market analysis, the competition between producers and manufacturers tends to be homogenized, and consumers' consumption mentality is becoming mature and numb. From the analysis of the internal reasons of the enterprise, the value provided by advertising does not conform to the values of consumers, lacks creativity and is unattractive. If the marketing strategy of user co-creation of advertising is adopted, the efficiency of advertising can be greatly improved from inside to outside, and the publicity concept in line with consumer values can be adopted to break through the traditional forms of advertising and carry out precise marketing [7].

\subsection{The benefits of user co-creation of advertising to brand building}

\subsubsection{Analyze the brand building advantage from the perspective of the enterprise}

From the perspective of enterprises, as the competitive environment becomes increasingly fierce, enterprises should take the initiative to include customers in the production of product advertisements to better meet their needs, which is an active demand of enterprises in the face of environmental pressure. When the product homogenization is serious, the advertising 
mode plays a more important role in highlighting the brand value. First, customer participation is conducive to the enterprise to obtain creative ideas, and customers are more likely to produce more original ideas than enterprise developers. The customer becomes the creator of the joint advertisement, strengthening the interaction between the customer and the producer can improve the level of creativity. Second, customers participate in the production of brand advertising and integrate their accepted and recognized ideas and values into the brand can improve customers' satisfaction with the brand and products; Third, the needs of the new advertising market, customer participation in advertising production will be conducive to continuous communication between enterprises and customers, which will help enterprises understand the form of advertising, content value, style characteristics and customer preferences and other key factors affecting the spread of brand value, effectively improve the quality of advertising [13].

In addition, brand value dissemination can be maximized. By strengthening the cooperation with customers, enterprises can understand the advertising market and customer demand, and by integrating customers' ideas, knowledge, ability and demand, they can better realize the innovation of advertising, and brand value is more easily recognized by the market, so as to bring profits to enterprises. Similarly, customers also hope to exert their abilities and wisdom through participating in the process of value co-creation, in which they can better put forward and meet their own needs [14].

\subsubsection{Analyze the brand building advantage from the perspective of the users}

From the perspective of users, users' active participation in advertising creation can strengthen brand identity and achieve self-adjustment of consumers' brand impression. Brand identity is an extension in the field of consumer society identity, is acquired through their own specific consumer behavior and consumer product symbols to express, communicate and display ourselves a social identity, the identity is self-concept and brand concept consistency of perception, is reflects in the consumers' brand evaluation of self-image and social image. In other words, consumers realize their own demand for "identity" through the creation of advertising content, and obtain the corresponding personal values; On the other hand, it forms a connection with other members of the brand community through this identity, which not only strengthens the brand collective, but also obtains the shared brand label with other members to be recognized by others, and becomes a power tool to maintain the brand collective [3]. As a result, shared brand values and brand labels are formed between enterprises and consumers. Economic development and social progress make people's consumption more for the construction of self-concept, the establishment of personal identity and the development of personal meaning, the purpose of consumption to meet the physical value of physiological needs to meet personalized, self-realization and other virtual values related to self-concept [5]. Value co-creation in the marketing field is customer-led, and customers can integrate environmental factors and their own factors into the creative advertising, so as to make the brand value fit with its preferences, so as to better meet the personalized needs of customers and enhance the brand value. The higher the customer satisfaction is, the higher the customer perception and recognition of the product can be enhanced, and then customers can be more actively involved in the process of value creation to form a virtuous cycle, and also affect the purchase intention and word-of-mouth effect [12].

\subsubsection{Promotion strategy of co-creating advertising}

Driven by digital technology, brand advertising should be expanded by digital integration thinking [2]. To break through the original traditional media thinking, identify the consumer's key brand contact point; Within the scope of controllable risks, enterprises should constantly increase the openness of business operation, and bring many links of internal business management into the brand contact of consumers, so that enterprises' internal management, like external marketing communication, become the brand contact point of consumption. At the same time, we should have a deep insight into consumer groups and consumer trends. Generation $\mathrm{Z}$ has gradually become the main force of current consumption, so brands should gradually change their strategies to cope with market changes according to the characteristics of Generation Z [8]. Growing up in the information age, they are influenced by all-round multi-culture and have unique and individual personalities. Careful observation of the whole marketing process of Soup's got talent will also find that innovation, interaction, personality, creativity, the characteristics of these young people can also be found in its marketing, "user ism" is implemented. In addition, the threshold of advertising co-creation should also be lowered to improve the enthusiasm of users to participate, so as to have a wider range of audiences to provide more ideas [10].

\section{DISCUSSION}

As generation $\mathrm{Z}$ consumers become the main consumers, they are more creative, proactive and expressive, hoping to participate in brand building instead of passively waiting for brands to push products and content information, and the leading role of consumers in value co-creation is gradually increasing [9]. At present, many enterprises actively create content 
and value with consumers in the product field, but in the marketing field, the co-creation ability of enterprises still needs to be strengthened. User and enterprise jointly participate in advertising creation is advantageous to the spread of brand building and brand value, based on the logic of consumers interact as the leading brand value to create a path selection is an important part of the marketing, it will "consumers to participate in the" create value "concept as the core of the brand construction, such as a certain extent, represents the future trend of the brand management and development of the important, It will also be the key to the success or failure of the market [11].

\section{CONCLUSION}

The theory of value creation changes with the development of The Times. Enterprises are no longer the single value creator. Consumers participate in the process of value creation, become the creator, and use their own knowledge and skills to integrate resources with enterprises to create value together. With the development of the network era, co-creation of advertising by users in the network environment is an excellent way of co-creation of value. User participation in the creation of advertising, for enterprises, can promote the innovation of advertising content and form, improve the quality of advertising, easier to be recognized by the market and increase the profitability of enterprises; For users, the integration of their own values and ideas into brand advertising enhances the recognition and connection of users to the brand, expands the associated user groups, and improves the overall value of the brand. Enterprises should make good use of the marketing means of user advertising and co-creation, integrate marketing resources according to the characteristics of generation $\mathrm{Z}$ users, and enhance brand value through the use of network platform. At present, only a few enterprises have adopted the method of user-co-created advertising, and the analysis of cases and data is insufficient. Therefore, more cases are needed to discuss this strategy.

\section{Acknowledgement}

Firstly, I would like to show my deepest gratitude to my teachers and professors in my university and research program, who have provided me with valuable guidance in every stage of the writing of this thesis. They guided me in right direction when I had some difficulties. Digital marketing and advertising is a new field for me and I am very grateful to the teachers for passing on their knowledge and answering my questions to give me a foundation for my dissertation. In addition to this, I have also been able to put my knowledge into practice through various projects carried out by my teachers to gain a deeper understanding. All of this would not have been possible without the support of my teachers. Further, I would like to thank all my friends and parents for their encouragement and support. Without all their enlightening instruction and impressive kindness, I could not have completed my thesis.

\section{Reference}

[1] Yu yiyong \& Yang Zhong.(2019). A review of the connotation and internal mechanism of value co-creation. University (02) 165-172.

[2] Xi luyang.(2020). Research on the model and core path of corporate brand value co-creation System -Based on the perspective of the dominant logic of consumer participation. Enterprise Economics (01),36-41.

[3] Zeng Linying \& Qi Yue. (2021). Research on Network Marketing Mode based on value co-creation. Modern Marketing (Academic Edition) (06),21-23.

[4] Qian Xuchao, Wang Xuewei \& Chen Qingqing. (2020). Research on the Realization path of value commitment in the Process of brand Growth -Based on the perspective of value co-creation. Management Modernization (03),106-111.

[5] Li Xuying.(2020). The impact of customer participation value co-creation on brand trust in virtual brand community. Chinese and Foreign enterprise culture (10), 15-16.

[6] Yang, N. (2021). The relationship between customer participation value co-creation and brand image building. Science Research management,87-93.

[7] Chen, Weichao \& Pi, Yuexin. (2020). Innovative strategies of community marketing on beeping website from the perspective of value co-creation. Journal of Hunan Engineering College (Social Science Edition) (04), 30-34+42.

[8] Zhu Ting. (2019). A study of social media-driven user relationship construction, maintenance, and deepening (Doctoral dissertation, Huazhong University of Science and Technology).

[9] Liu Manxing. (2021). The communication dilemma of short video advertising and strategies to cope with it. News World (10), 26-29.

[10] She, Hui-Ling \& Gong, Li-Ying. (2020). Exploring the value co-creation model of digital reading platforms in the age of social media. Publishing and Distribution Research (11), 50-57+49.

[11] Key. (2021). The new consumer brands: Generation Z's "sweet tooth". Business Management (10), 31-33. 
[12] Du, Y. Z. \& Zhao, J.. (2021). The influence of customer perceived value on brand love - Based on the mediating role of consumer trust. Research in Business Economics (19), 83-87.

[13] Lu, S.L. \& Lu, L.Y.. (2021). An analysis of the value and management strategies of brands. Wealth Today (20), 67-69.

[14] Sun Wei (2021-09-29). Consumers pay more attention to brands. China Consumer News, 002. 